\title{
Editorial
}

\section{Anteproyecto de la Ley de Dependencia}

5

Aunque con una demora importante sobre lo acontecido en otros países de nuestra área de relación, hace unas semanas ha visto la luz el anteproyecto de Ley denominada de Promoción de la autonomía personal y atención a las personas en situación de dependencia.

Se inicia finalmente un debate que, a pesar de sus altibajos y seguras metamorfosis en los próximos meses, dará a luz un nuevo derecho para todos los españoles, reconociendo en primera instancia y garantizando, o al menos en proceso de hacerlo, la atención y cuidados a las personas dependientes. Este gran reto de política social que desde ésta y otras muchas plataformas, desde el discurso de nuestra profesión y la de otros gerontólogos, venimos reclamando, está servido y sin duda precisará de una respuesta firme de todas las Administraciones Públicas, de todos los partidos políticos y del completo de la ciudadanía para llevarlo al puerto que ofrece y merece.

Por primera vez se va a sobrepasar el reconocimiento consolador de un orador de turno de ese derecho de las personas -muchas de ellas mayores- que precisan de apoyo y cuidados "para poder ejercer sus derechos de ciudadanía, acceder a los bienes sociales y desarrollar sus actividades más esenciales de la vida diaria”, como reza la exposición de motivos de este anteproyecto. Se trata con esta futura ley de garantizar un marco estable y duradero de recursos y servicios para la atención de las personas dependientes. El Estado, finalmente, intervendrá con una nueva acción protectora que "amplía y complementa" la acción protectora del Sistema de la Seguridad Social, desarrollando un nuevo pilar básico, el Sistema Nacional de Dependencia, que garantizará esas condiciones básicas de prestaciones y servicios, en comunión con la totalidad de las Comunidades Autónomas y en razón directa al número de personas dependientes residentes en ellas.

La llamada de las cifras, el eco del reiterado impacto de la atención de éste cada vez más creciente grupo de población, la afinidad preferente de la discapacidad por la población mayor, eje de nuestro trabajo, las dificultades aumentadas de las familias, tradicionales y únicas cuidadoras de estas personas dependientes, para continuar abasteciendo "en exclusiva", creemos que han podido ser los detonantes de este anteproyecto, y en breve ley, que tratará de atenuar la precariedad existente en recursos, servicios y también profesionales dedicados a este grupo específico.

La Ley definirá servicios y prestaciones, trabajará en la delimitación de los grados de dependencia, los criterios básicos para su valoración, el catálogo mínimo de servicios a los que todos los españoles, independientemente de su origen o lugar de residencia, tendrán derecho. También las familias que sigan proporcionando el cuidado en el entorno familiar tendrán su recompensa. Estamos firmemente convencidos de que esta Ley y el hoy embrión del Sistema Nacional de Dependencia precisan de la cooperación de todas las instancias y Administraciones para asegurar su durabilidad y la eficacia buscada. Se abren desde este momento importantes y difíciles cuestiones en la construcción final de una ley básica y de justicia. Los sistemas de financiación de la misma, las formas de preservar la equidad entre los ciudadanos de distintas regiones, los calendarios para su puesta en marcha y desarrollo completo, las resistencias por parte de ciertos agentes, que tendrán que justificarlas sin quedar, como hasta la fecha, en evidencia flagrante. De la mano de esta Ley renacerán debates sobre la formación de profesionales y cuidadores familiares, desarrollo innovador de fórmulas asistenciales, seguros de dependencia, proliferación del mercado de recursos para las personas dependientes y un amplio etcétera, sobre los que -amenazamos- iremos dando nuestra opinión. Éste hoy proyecto y mañana ley abre sin duda un escenario de importante valor y realce, cuantitativo y deseamos que también cualitativo, para la enfermería gerontológica y otras disciplinas, como la nuestra, dedicadas a la atención de los más veteranos de esta sociedad. Transcurrido cerca de un cuarto de siglo de sus predecesores Sistemas Nacionales, de Salud, Educación y Pensiones, celebremos desde hoy el nacimiento de este cuarto pilar del Estado del Bienestar para nuestro país, e invitemos a cada instancia posible a apoyar su solidez y durabilidad.

Las personas dependientes y sus familias han comenzado a ver la luz. La plenitud de acción de esta próxima Ley tardará todavía unos pocos años, pero el camino se ha iniciado y quiero felicitar desde esta tribuna a todos los que la han hecho posible y en unos meses articularán un texto "de peso".

J. Javier Soldevilla Agreda Director GNEAUPP 